\title{
Outorgas consuntivas: análise hídrica no Município de Unaí - MG
}

\author{
Consumption grants: water analysis in the Municipality of Unaí - MG \\ Ayudas al consumo: análisis de aguas en el Municipio de Unaí - MG
}

Recebido: 13/03/2021 | Revisado: 20/03/2021 | Aceito: 21/03/2021 | Publicado: 28/03/2021

\author{
Marinaldo Loures Ferreira \\ ORCID: https://orcid.org/0000-0002-8106-2793 \\ Universidade Federal dos Vales do Jequitinhonha e Mucuri, Brasil \\ E-mail: marinaldo79@gmail.com \\ André Medeiros de Andrade \\ ORCID: https://orcid.org/0000-0003-3502-7847 \\ Universidade Federal dos Vales do Jequitinhonha e Mucuri, Brasil \\ E-mail: andre.medeiros@ufvjm.edu.br \\ Wesley Esdras Santiago \\ ORCID: https://orcid.org/0000-0003-1775-5701 \\ Universidade Federal dos Vales do Jequitinhonha e Mucuri, Brasil \\ E-mail: wesley.santiago@ufvjm.edu.br
}

\begin{abstract}
Resumo
O Brasil é um país privilegiado quanto à disponibilidade hídrica total, no entanto sua distribuição é desigual no território, tornando a outorga um instrumento necessário para o gerenciamento dos recursos hídricos. Portanto, este estudo objetiva analisar as outorgas vigentes e confrontá-las com a demanda dos pivôs centrais instalados dentro do limite do município de Unaí - MG. Para o estudo, foram utilizados dados de outorgas de dominialidade federal disponibilizados pela ANA no portal de Regulação e dados de outorgas no âmbito Estadual disponibilizado pelo Instituto Mineiro de Gestão das Águas - IGAM. Dados estes, manipulados através das técnicas de geoprocessamento para obtenção dos resultados. O município de Unaí possui um total de 420 concessões de outorgas de captação superficial, sendo 346 de dominialidade federal e 74 de dominialidade do estado Mineiro, cuja vazão total outorgada equivale a $56,3 \mathrm{~m}^{3} \mathrm{~s}^{-1}$, sendo maior que a demanda calculada de todos os pivôs centrais do município de Unaí concomitante com a cultura do milho safrinha, vazão em torno de $35,1 \mathrm{~m}^{3} \mathrm{~s}^{-1}$. Cabe destacar que poderá haver algumas incertezas em relação aos dados, pois sabe-se que ainda existem usos não regularizados, limitando o cálculo da demanda sobre as outorgas existentes nos bancos de dados dos órgãos responsáveis.
\end{abstract}

Palavras-chave: Recursos hídricos; Irrigação; Outorga de uso da água.

\begin{abstract}
Brazil is a privileged country in terms of total water availability; however, its distribution is uneven in the territory, making the grant a necessary instrument for the management of water resources. Therefore, this study aims to analyze the current grants and confront them with the demand of the central pivots installed within the limit of the municipality of Unaí - MG. For the study, data from grants of federal dominance made available by ANA on the Regulation portal and data from grants at the State level made available by the Mineiro Institute of Water Management - IGAM were used. These data, manipulated through geoprocessing techniques to obtain the results. The municipality of Unaí has a total of 420 surface abstraction granting concessions, 346 of which are federally owned and 74 of which are owned by the state of Minas Gerais, whose total flow granted is equivalent to $56.3 \mathrm{~m}^{3} \mathrm{~s}^{-1}$, being greater than the estimated demand for all central pivots in the municipality of Unaí concomitant with the cultivation of safrinha corn, flow around $35.1 \mathrm{~m} \mathrm{~m}^{3} \mathrm{~s}^{-1}$. It should be noted that there may be some uncertainties in relation to the data, as it is known that there are still unregulated uses, limiting the calculation of the demand on the existing grants in the databases of the responsible agencies.
\end{abstract}

Keywords: Water resources; Irrigation; Granting of water use.

\section{Resumen}

Brasil es un país privilegiado en términos de disponibilidad total de agua, sin embargo, su distribución es desigual en el territorio, lo que hace de la donación un instrumento necesario para la gestión de los recursos hídricos. Por tanto, este estudio tiene como objetivo analizar las ayudas actuales y confrontarlas con la demanda de los pivotes centrales instalados dentro del límite del municipio de Unaí - MG. Para el estudio, se utilizaron datos de concesiones de dominio federal puestos a disposición por ANA en el portal de Regulación y datos de concesiones a nivel estatal puestos a disposición por el Instituto Mineiro de Gestión del Agua - IGAM. Estos datos, manipulados mediante técnicas de geoprocesamiento para obtener los resultados. El municipio de Unaí tiene un total de 420 concesiones de extracción de superficie otorgadas, de las cuales 346 son de titularidad federal y 74 del estado de Minas Gerais, cuyo 
caudal total otorgado equivale a $56,3 \mathrm{~m}^{3} \mathrm{~s}^{-1}$, siendo mayor que la demanda estimada para todos los pivotes centrales en el municipio de Unaí concomitantes con el cultivo de maíz safrinha, fluyen alrededor de $35,1 \mathrm{~m}^{3} \mathrm{~s}^{-1}$. Cabe señalar que pueden existir algunas incertidumbres en relación a los datos, ya que se sabe que aún existen usos no regulados, limitando el cálculo de la demanda sobre las subvenciones existentes en las bases de datos de los organismos responsables.

Palabras clave: Recursos hídricos; Irrigación; Concesión de uso de agua.

\section{Introdução}

O uso da água tem aumentado globalmente em cerca de $1 \%$ ao ano, impulsionado por uma combinação de crescimento populacional, desenvolvimento socioeconômico e mudanças nos padrões de consumo, portanto, seguindo este ritmo, há previsão que esta demanda global de água continue aumentando até 2050 (UNESCO, 2019). Embora a água seja o elemento mais abundante na superfície terrestre, a água está cada vez mais escassa e as razões são de origens antrópicas (FAO, 2012; EMBRAPA, 2020; UN, 2020).

A água é um bem ambiental essencial à vida e fundamental para o desenvolvimento das culturas (Rosa et al., 2020). A partir do momento em que se agrega a ela valor econômico passa a ser denominada como recurso hídrico (Cantelle et al., 2018). E de acordo com a Lei $\mathrm{N}^{\circ}$ 9.433/1997, a água é um bem de domínio público, sendo um recurso natural limitado, dotado de valor econômico, e sua gestão deve sempre proporcionar o uso múltiplo.

Sabendo-se que a água é um recurso essencial para o ser humano, um bem de alto valor social e econômico, passível de conflitos de usos consuntivos, torna-se necessária a regulação jurídica no âmbito de reger as atividades humanas relacionadas a esse bem (Aith \& Rothbarth, 2015). Portanto, atendendo a esta demanda, foi criada a Outorga de Direito de Uso de Recursos Hídricos, constituindo um instrumento fundamental no que se refere aos mecanismos de controle dos usos da água (Deus \& Latuf, 2019). Sendo um dos instrumentos da Política Nacional de Recursos Hídricos, estabelecido no inciso III, artigo $5^{\circ}$ da Lei Federal 9.433/1997, bem como da Política Estadual de Recursos Hídricos de Minas Gerais, nos termos do inciso V, artigo $9^{\circ}$ da Lei Estadual 13.199, de 29 de janeiro de 1999.

A Política Nacional de irrigação disciplina o novo marco legal e busca regulamentar o processo de modernização no campo (Rodrigues \& Domingues, 2017). E que de modo geral, objetiva o incentivo a ampliação da área irrigada e ao aumento da produtividade respeitando as bases ambientalmente sustentáveis, concorrendo para o aumento da competitividade do agronegócio brasileiro e para a geração de emprego e renda (Lei nº 12.787, 2013).

Essa lei proporcionou avanços importantes que possibilitaram desenvolver a agricultura irrigada sustentável no país (Rodrigues \& Domingues, 2017). Resultando em 6,95 milhões de hectares equipados para irrigação utilizando diferentes técnicas de aplicação. Com destaque para os sistemas de aspersão por pivô central, que em 2017 representava 23.181 dispositivos em operação e área de 1 milhão e 476 mil hectares (ANA, 2019b).

O município de Unaí, objeto deste estudo, tem suas principais atividades econômicas relacionadas à produção agropecuária (Ribeiro et al., 2018). Contribui de forma expressiva na produção de grãos no Estado, se destacando por possuir a maior área equipada por pivôs centrais do país, um montante de 65.930 hectares (ANA, 2019b). Figurando entre os primeiros colocados no ranking de maior Produto Interno Bruto (PIB) agropecuário de Minas Gerais (IBGE, 2018).

Como o uso de sistemas de irrigação por pivô central é uma tendência crescente, o conhecimento sobre os recursos hídricos se torna importante, apoiando as decisões referente a gestão assim como o fomento da agricultura irrigada (Deines et al., 2017; Saraiva et al. 2020). Sendo a eficiência das outorgas, primordial para alcançar grande parte dos objetivos fundamentais e específicos do gerenciamento da água em uma determinada região (Sousa et al., 2017).

Neste contexto, o presente estudo objetiva analisar as outorgas vigentes e confrontá-las com a demanda dos pivôs centrais instalados dentro do limite do município de Unaí - MG. 


\section{Metodologia}

\section{1 Área de estudo}

A área de estudo corresponde ao município de Unaí, localizado no Noroeste de Minas Gerais (Figura 1). Está inserido no bioma Cerrado, com 8.448,08 $\mathrm{km}^{2}$ de unidade territorial (IBGE, 2019b). O clima é do tipo Aw, que corresponde ao clima tropical chuvoso, clima de savana, com predomínio de invernos secos (Köppen, 1948). A temperatura média anual das máximas oscila entre $29{ }^{\circ} \mathrm{C}$ e $31{ }^{\circ} \mathrm{C}$, e as mínimas entre $15{ }^{\circ} \mathrm{C}$ e $17{ }^{\circ} \mathrm{C}$, com umidade relativa média anual entre $65 \%$ e $72 \%$, variando sensivelmente com as estações do ano (EPAMIG, 2014). O regime pluviométrico da região caracteriza-se por um período chuvoso de outubro a abril, com o período seco prolongando-se por cinco meses, de maio a setembro, com precipitação média anual entre 1.322 e 1.618 mm (Silva et al., 2017).

Figura 1. Mapa de localização. A) Localização de Minas Gerais. B) Município de Unaí em Minas Gerais. C) Limite de Unaí.

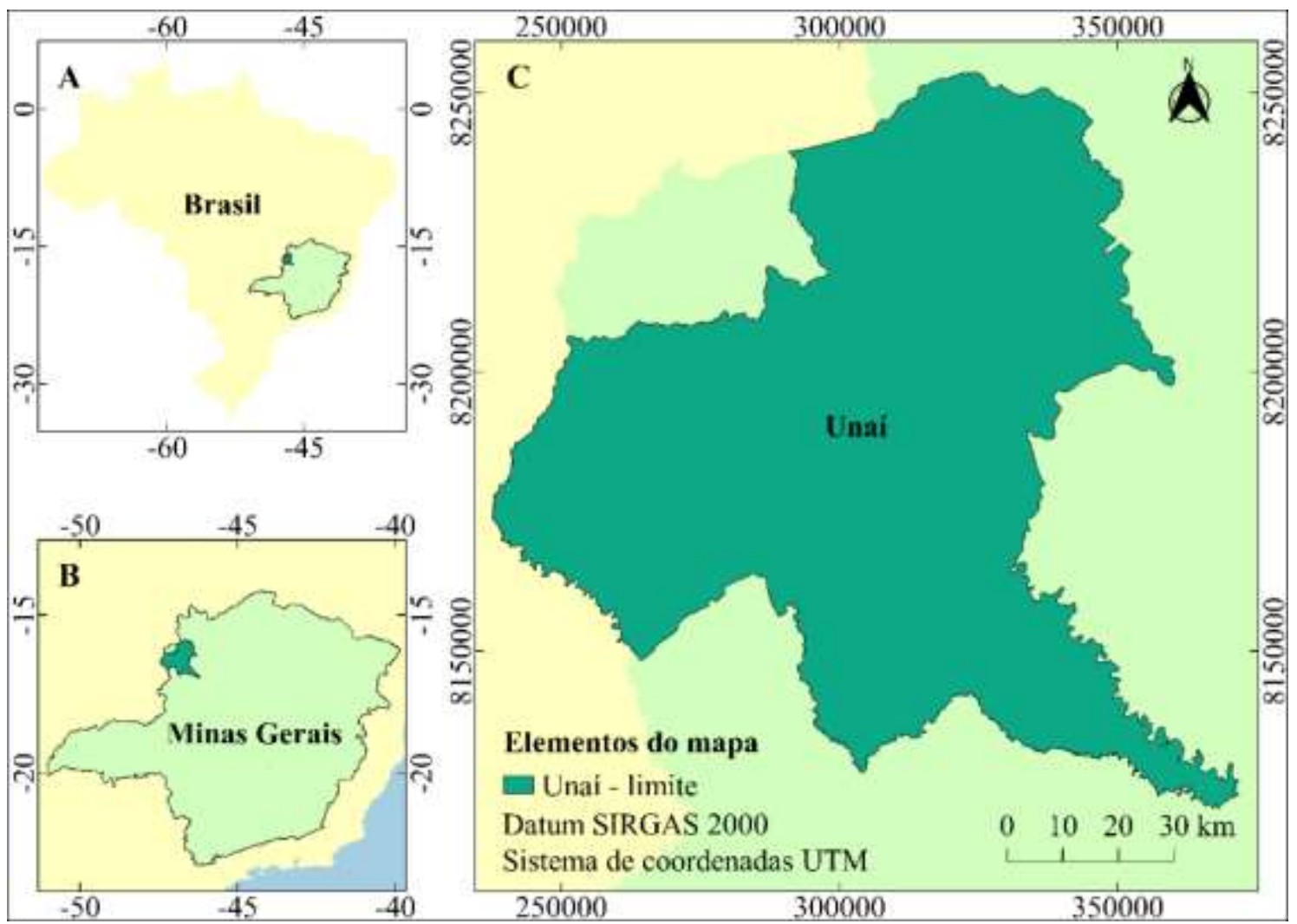

Fonte: Autores.

\subsection{Outorgas vigentes}

Para esta análise, foram utilizados dados de outorgas de dominialidade federal disponibilizados pela ANA no portal de Regulação. Os dados contêm informações até novembro de 2020, e os dados de outorgas no âmbito Estadual disponibilizados pelo Instituto Mineiro de Gestão das Águas (IGAM) contendo informações até o final de 2019, dados estes, comtemplando captações superficiais e subterrâneas.

A emissão dessas outorgas passa por um processo de análise criterioso, que consiste em compatibilizar, em uma determinada bacia hidrográfica, a disponibilidade hídrica e as demandas dos diversos usuários da água (Garcia et al., 2020). Portanto, o conhecimento das vazões mínimas dos rios e seus afluentes, são essenciais para a aplicação do instrumento de outorga, que nacionalmente, seguem duas abordagens como critério para a sua definição, seja pelas vazões mínimas com determinado tempo de recorrência ou pelas vazões de curva de permanência (ANA, 2019a). 
O estado de Minas Gerais, amparado pela Resolução Conjunta SEMAD-IGAM nº 1.548, de 29 de março de 2012, utiliza o critério de vazões mínimas com determinado tempo de recorrência, a Q7 10 e fixa a disponibilidade hídrica máxima outorgável para as captações de água em 50\% dessa vazão, salvo em locais específicos, sendo 30\% da Q710. Enquanto a ANA, adota o critério baseado nas vazões de curva de permanência, a Q ${ }_{95}$ e de acordo com Resolução ANA 542/2004, adota a vazão máxima outorgável de 70\% dessa vazão de referência, podendo variar em função das peculiaridades de cada região.

\subsection{Pivôs centrais ativos}

Os pivôs centrais ativos foram mapeados utilizando o Google Earth Engine (GEE), plataforma para análise científica, que usa processamento em nuvem do Google para sua própria análise geoespacial e visualização de dados (Kumar \& Mutanga, 2018). Foram utilizadas imagens de satélites de sensoriamento remoto transformadas em índice de vegetação realçado (Twoband Enhanced Vegetation Index - EVI 2).

$$
\text { EVI } 2=2,5 * \frac{N I R-R E D}{(N I R+2,4 * R E D+1)}
$$

Onde 2,5 e 2,4 são fatores de ajuste do processo de calibração do índice de vegetação (Jiang et al., 2008).

Foram utilizadas imagens da coleção do satélite Sentinel-2 do ano de 2019, sendo manipuladas dentro da plataforma do GEE, transformadas no índice de vegetação EVI 2 e exportadas para o Google Cloud Platform, que posterior foi inserida no software de geoprocessamento para identificação visual dos pivôs.

\section{Resultados e Discussão}

Analisando somente as outorgas de captações superficiais de usos consuntivos no município (Figura 2), observa-se um total de 420 concessões, sendo 346 de responsabilidade federal (emitidas pela ANA) e 74 concessões de responsabilidade do estado de Minas Gerais (emitidas pelo IGAM). Em resumo, as outorgas hídricas do município de Unaí são de responsabilidade da ANA, no que tange a união e de responsabilidade do IGAM, referente a domínio do estado. 
Figura 2. Distribuição das outorgas de usos consuntivos no município de Unaí - MG.

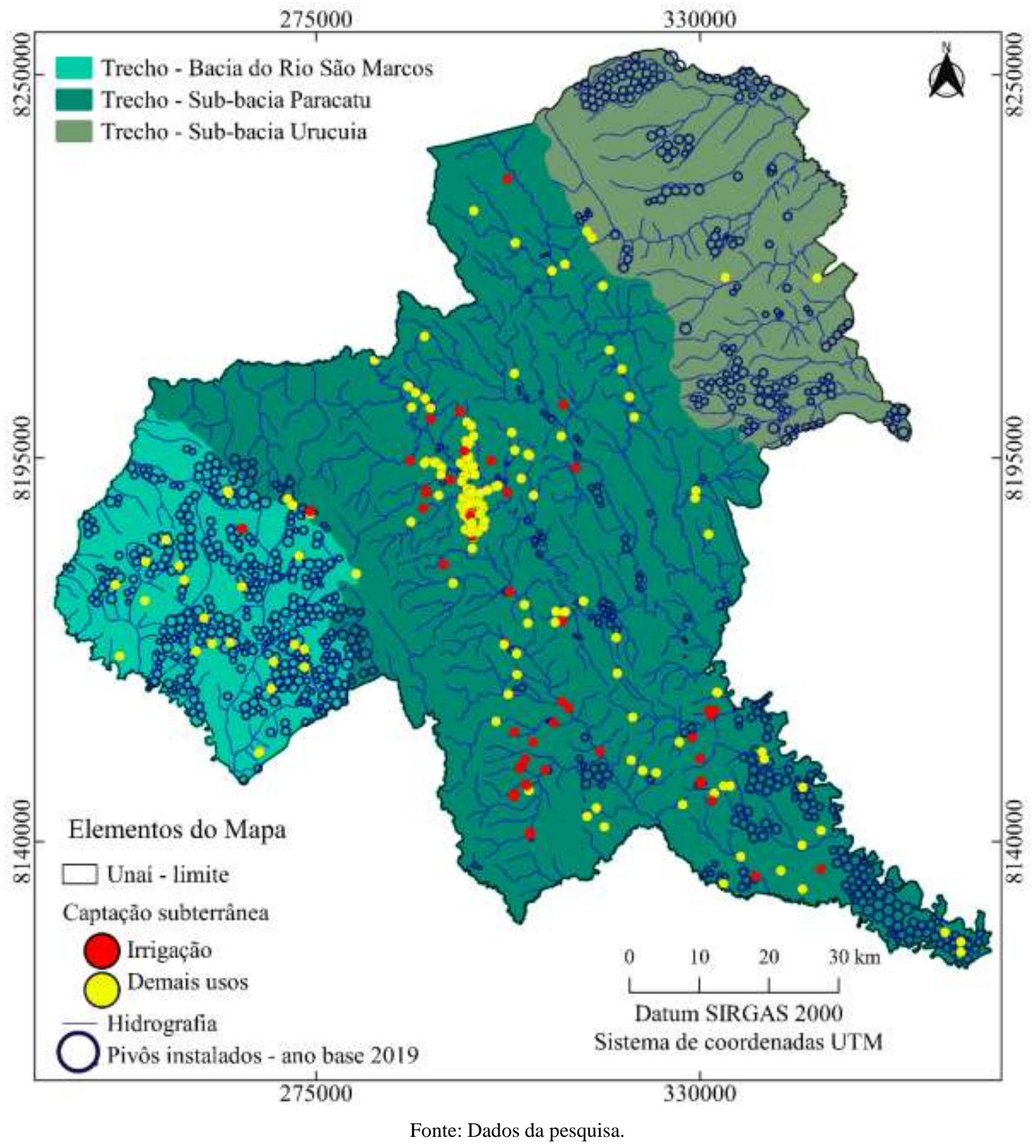

Das outorgas vigentes, 90,0\% são destinadas a irrigação de forma geral, atendendo os sistemas de irrigação por pivô central, aspersão convencional, assim como, sistema de irrigação por gotejamento e micro aspersão (Tabela 1). No âmbito federal são 246 pontos de captação outorgados especificamente para pivô central, informação esta, observada no relatório de regulação disponibilizado pela ANA. No âmbito estadual, foram observados 58 pontos outorgados para irrigação via pivô central, portanto, esta informação não está contida no arquivo do IGAM, foram observadas pelas coordenadas disponibilizadas e visualizadas próximas a pivôs instalados na área de estudo. 
Tabela 1. Números de outorgas de captações superficiais do município de Unaí - MG, separadas por tipos de usos.

\begin{tabular}{lccc}
\hline Uso consuntivo & Outorgas ANA & & Outorgas IGAM \\
\cline { 1 - 2 } Abastecimento Público & 2 & - \\
Aquicultura em Tanque Escavado & 3 & - \\
Consumo Humano & 5 & 1 \\
Criação Animal & 17 & 2 \\
Indústria & 1 & - \\
Irrigação & 312 & 66 \\
Outras & 6 & 5 \\
\hline
\end{tabular}

Fonte: Adaptado da ANA e IGAM (2020).

O quantitativo expressivo de outorgas destinadas a irrigação via pivô central observado, traduz o quanto as atividades econômicas da área de estudo estão relacionadas a produção de grãos via agricultura irrigada (Ribeiro et al., 2018). Destas outorgas destinadas a este sistema de irrigação, considerando as duas dominialidades, 83,0\% (252 pontos de captação) estão localizadas dentro da sub-bacia Paracatu. Captações estas, destinadas a atender 268 pivôs instalados (21.638 hectares) de acordo com o a análise visual dos pivôs centrais em atividade no município de Unaí no ano de 2019. Outros 10,0\% (31 pontos) estão localizados na bacia do Rio São Marcos, no entanto, precisam atender 352 pivôs instalados (31.084 hectares). E por fim, 7,0\% (21 pontos outorgados) estão dentro da área da sub-bacia Urucuia, destinados a atender 178 pivôs instalados (16.151 hectares).

Observa-se, que na sub-bacia Paracatu, os pivôs estão menos concentrados que nas demais áreas do estudo, justificando o maior número de outorgas para atender o quantitativo de pivôs instalados. Ademais, em uma análise visual, observou-se, que 54 pontos de captação dentro da sub-bacia Paracatu são classificados nos arquivos ANA como atendimento a irrigação via pivô central, no entanto, não estão sendo aplicados a este fim.

De acordo com os dados, o município de Unaí possui uma vazão média outorgada de $54,6 \mathrm{~m}^{3} \mathrm{~s}^{-1}$ de água sob dominialidade da ANA, e deste total, 49,6 $\mathrm{m}^{3} \mathrm{~s}^{-1}$ são destinados a irrigação por pivô central, representando 90,7\% do total outorgado. O IGAM, no entanto, tem outorgado $7,1 \mathrm{~m}^{3} \mathrm{~s}^{-1}$, sendo $6,7 \mathrm{~m}^{3} \mathrm{~s}^{-1}$ destinados a irrigação por pivô central, ou seja, 94,4\% das águas outorgadas sob dominialidade do estado no município, se destinam a irrigação via pivô central. Resultados condizentes com a realidade econômica do município, que se destaca pela agricultura irrigada, tendo a maior área equipada por pivôs centrais do país (ANA, 2019b).

A análise visual dos pivôs centrais em atividade no município de Unaí no ano de 2019 identificou 798 pontos pivôs em uma área de 68.872 hectares. Avaliando estes dados, os resultados mostram que a demanda calculada de todos os pivôs centrais do município supostamente concomitante com a cultura do milho safrinha, demandaria uma vazão média em torno de $35,1 \mathrm{~m}^{3} \mathrm{~s}^{-1}$, considerando a lâmina de 4,4 $\mathrm{mm} \mathrm{dia}^{-1}\left(0,51 \mathrm{~L} \mathrm{~s}^{-1} \mathrm{ha}^{-1}\right)$ encontrada pelo estudo de Oliveira e Silva (2009) para a porção do Distrito Federal e Goiás dentro da Bacia do rio São Marcos. Bacia esta, que abrange 15\% da área do município de Unaí. Portanto, esta vazão hipotética ainda é menor que a vazão outorgada de acordo com os dados levantados, que somados equivalem a $56,3 \mathrm{~m}^{3} \mathrm{~s}^{-1}$. Ressalta-se, que o inventário de cadastros e outorgas de uso da água é útil para diversas aplicações, mas não reflete a real precisão quanto aos volumes efetivamente utilizados, visto que o valor outorgado tende a um limite máximo de abastecimento, assim, as vazões médias efetivas tendem a ser inferiores, especialmente para grandes usuários (ANA, 2019c). 
Analisando as outorgas subterrâneas concedidas no município (Figura 3), verifica-se 253 pontos de captação destinadas a vários usos, cuja vazão total da retirada fica em torno de $3.052,50 \mathrm{~m}^{3} \mathrm{~h}^{-1}$, sendo $61,5 \%$ (156 captações) destinadas a consumo humano, 23,0\% (58 captações) destinadas a irrigação, 10,0\% (26 captações) destinadas a abastecimento público e 5,5\% (14 captações) destinadas a dessedentarão de animais, assim como outros usos de acordo com os dados do IGAM. Na visão de Paixão et al. (2019), é importante a relação entre corpos d'água superficiais e subterrâneos, pois, não se pode ignorar o fato de que as vazões mínimas, que regulam as outorgas superficiais, são ajustadas pela água liberada pelos aquíferos.

Figura 3. Distribuição das outorgas subterrâneas no município de Unaí - MG.

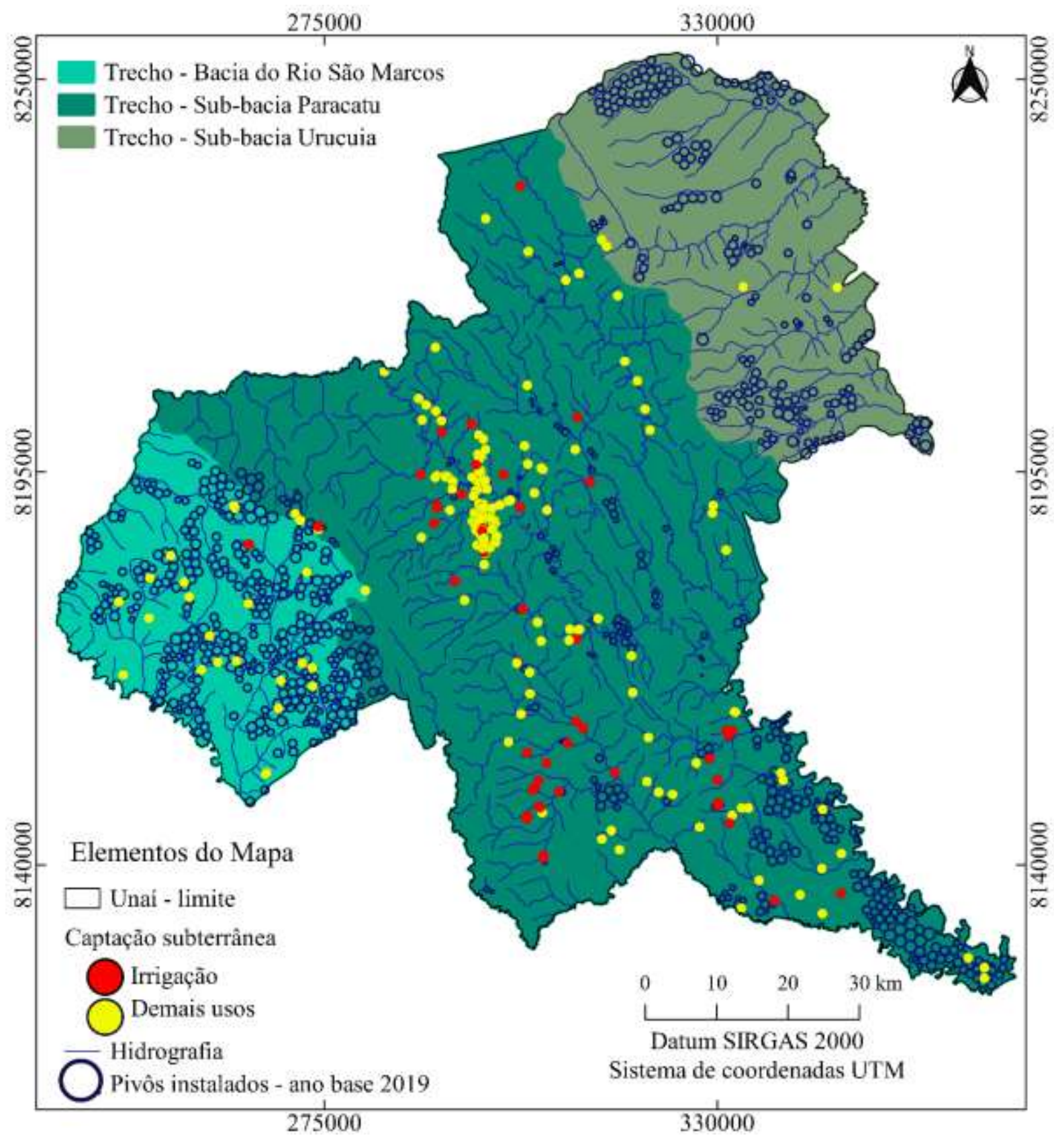

Fonte: Dados da pesquisa.

Das captações subterrâneas voltadas para a irrigação, 13 destas outorgas estão referidas a metodologia de irrigação via pivô central, cujas vazões variam entre 30 a $100 \mathrm{~m}^{3} \mathrm{~h}^{-1}$, sendo 3 presentes na área da bacia do Rio São Marcos e 10 localizadas na sub-bacia Paracatu. Vale ressaltar, que as outorgas para uso de águas subterrâneas em Minas Gerais, precisam atender aos 
critérios estabelecidos na Deliberação Normativa Conjunta COPAM-CERH Nº 05 de 2017, onde de forma geral, estabelece diretrizes e procedimentos para controle do uso das águas subterrâneas, assim como outras providências.

\section{Considerações Finais}

Diante dos aspectos apresentados, observa-se a importância das outorgas para o gerenciamento dos recursos hídricos, pois, permite o controle quantitativo dos usos da água e contribui para que o uso deste recurso seja utilizado de forma responsável e racional.

O município de Unaí, possui um número considerável de captações superficiais destinadas a irrigação, correspondendo a 90,0\% das outorgas vigentes. Quanto as captações subterrâneas, a irrigação corresponde ao segundo uso preponderante, cerca de $23,0 \%$ das captações, ou seja, um recurso pouco explorado no município para tal finalidade devido suas particularidades.

No estudo, foi observado áreas com concentração de pivôs sem pontos de captações superficiais que pudessem atendê-los, o que motivou a avaliar as outorgas de retiradas subterrâneas, entretanto, as mesmas áreas observadas, não apresentaram pontos com captações subterrâneas destinadas a irrigação. Fato este, caracterizado pelos usos não regularizados, limitando o cálculo da demanda sobre as outorgas existentes nos bancos de dados dos órgãos responsáveis, assim como, as outorgas de captação subterrânea, cujos cadastros oficiais não refletem a real situação da explotação de água subterrânea no município, assim como em todo o estado.

\section{Referências}

Agência Nacional de Águas (2019a). Conjuntura dos recursos hídricos no Brasil 2019: informe anual / Agência Nacional de Águas. Brasília: ANA, 100 p. Agência Nacional de Águas (2019b). Levantamento da agricultura irrigada por pivôs centrais no Brasil (1985 - 2017). Brasília: ANA, 47 p.

Agência Nacional de Águas (2019c). Manual de Usos Consuntivos da Água no Brasil. Brasília: ANA, 75p.

Aith, F. M. A. \& Rothbarth, R. (2015). O estatuto jurídico das águas no Brasil. Estudos avançados, 29 (84), $163-177$.

Brasil (1988). Constituição da República Federativa do Brasil. Brasil: Senado Federal.

Cantelle, T. D., Lima, E. C. \& Borges, L. A. C. (2018). Panorama dos recursos hídricos no mundo e no Brasil. Revista em Agronegócio e Meio Ambiente, 11 (4), 1259-1282.

Deines, J. M., Kendall, A. D. \& Hyndman, D. W. (2017). Annual Irrigation Dynamics in the U.S. Northern High Plains Derived from Landsat Satellite Data. Geophysical Research Letters, 44 (18), 9350-9360.

Deliberação Normativa Conjunta COPAM-CERH No 05 (2017). Estabelece diretrizes e procedimentos para a definição de áreas de restrição e controle do uso das águas subterrâneas e dá outras providências. Diário do Executivo, Belo Horizonte.

Deus, F. O. \& Latuf, M. O. (2019). Outorga e suas implicações na piscicultura no entorno do reservatório de Furnas. Caderno de Geografia, 29 (2), 2318 2962 .

Empresa Brasileira de Pesquisa Agropecuária (2020). Dinâmica da produção agropecuária e da paisagem natural no Brasil nas últimas décadas. Brasília: Embrapa.

Empresa de Pesquisa Agropecuária de Minas Gerais (2014). Solos e avaliação do potencial agrossilvipastoril das microrregiões Paracatu e Unaí - Minas Gerais. Belo Horizonte: EPAMIG, 106 p.

Food and Agriculture Organization of the United Nations (2012). Coping with water scarcity An action framework for agriculture and food security. Rome: FAO Water Reports.

Garcia, A. B. G., Sousa, I. F., Monteiro, A. S. C. \& Santana, N. R. F. (2020). Caracterização ambiental e hidrológica da bacia hidrográfica do Rio Jacarecica. Belo Horizonte: Poisson, 2020.

Instituto Brasileiro de Geografia e Estatística (2018). Produção Agrícola Municipal 2019. https://cidades.ibge.gov.br/brasil/mg/unai/pes quisa/38/46996?tipo=ranking\&indicador $=47006 \&$ ano $=2018$

Jiang, Z., Huete, A. R., Didan, K. \& Miura, T. (2008). Development of a two-band enhanced vegetation index without a blue band. Remote Sensing of Environment, 112 (10), 3833-3845. 
Research, Society and Development, v. 10, n. 4, e1610413858, 2021

(CC BY 4.0) | ISSN 2525-3409 | DOI: http://dx.doi.org/10.33448/rsd-v10i4.13858

Köppen, W. (1948). Climatologia: con un studio de los climas de la tierra. México: Fondo de Cultura Economica, 479 p.

Kumar, L. \& Mutanga, O. (2018). Google Earth Engine Applications Since Inception: Usage, Trends, and Potential. Remote Sensing, 10 (10), 1-15.

Lei no 12.787 (2013). Dispõe sobre a Política Nacional de Irrigação. Diário Oficial da União, Brasília.

Lei no 9.433 (1997). Política Nacional de Recursos Hídricos. Diário Oficial da União, Brasília.

Oliveira, L. \& Silva, M. (2009). Regionalização da lâmina suplementar de irrigação e época de semeadura do milho no estado de Goiás e Distrito Federal. Bioscience Journal, 25 (4), 43-52.

Paixão, M. M. O. M., Carvalho, J. L. G., Prates, L. \& Galvão, P. A. (2019). Condição de Explotação de Água Subterrânea em Minas Gerais à Luz dos Critérios da Deliberação Normativa Conjunta COPAM-CERH 05/2017. Águas Subterrâneas, 33 (4), 378-391.

Ribeiro, E. C., Gastal, M. \& Melo, T. (2018). Tipificação de sistemas de produção em assentamento de reforma agrária no município de Unaí, MG. Interações, $19(1), 171-180$

Rodrigues, L. N. \& Domingues, A. F. (2017). Agricultura irrigada: desafios e oportunidades para o desenvolvimento sustentável. Brasília: INOVAGRI.

Rosa, L., Chiarelli, D. D., Rulli, M. C., Dell'angelo, J. \& D’odorico, P. (2020). Global agricultural economic water scarcity. Environmental Sciences, 6 (18), eaaz6031.

Saraiva, M., Protas, É., Salgado, M. \& Souza, C. (2020). Automatic Mapping of Center Pivot Irrigation Systems from Satellite Images Using Deep Learning. Remote Sensing, $12(3), 558$.

Silva, D. V., Cunha, F. F., Vicente, M. R., Alencar, C. A. B. \& Souza, I. P. (2017). Análise de precipitação, balanço hídrico climatológico e classificação climática no município de Unaí-MG. Brazilian Geographical Journal: Geosciences and Humanities research medium, 8 (1), 68-82.

Sousa, F. R. L., Santos, V. S., Oliveira, M. M., Vale, J. R. L. \& Pessoa, M. F. (2017). Outorgas de direito de uso dos recursos hídricos no Alto Curso do rio Piranhas no Sertão da Paraíba. Revista Verde de Agroecologia e Desenvolvimento Sustentável, 12 (5), 843-848.

Testezlaf, R. (2017). Irrigação: métodos, sistemas e aplicações. FEAGRI.

United Nations (2020). Annual Report 2019. Water.

United Nations Educational, Scientific and Cultural Organization (2019). The United Nations World Water Development Report 2019: Leaving No One Behind. UNESCO. 